Andrea L.Williams, UNIVERSITY OFTORONTO,al.williams@utoronto.ca Roselynn Verwoord, UNIVERSITY OF BRITISH COLUMBIA, rverwoor@uvic.ca Theresa A. Beery, UNIVERSITY OF CINCINNATI, theresa.beery@uc.edu Helen Dalton, UNIVERSITY OF SYDNEY, helen.dalton@sydney.edu.au James McKinnon, VICTORIA UNIVERSITY OF WELLINGTON, James.McKinnon@vuw.ac.nz

Karen Strickland, EDINBURGH NAPIER UNIVERSITY, K.Strickland@napier.ac.uk Jessica Pace, MCMASTER UNIVERSITY, paceje@mcmaster.ca Gary Poole, UNIVERSITY OF BRITISH COLUMBIA, gpoole@exchange.ubc.ca

\title{
The Power of Social Networks: A Model for Weaving the Scholarship of Teaching and Learning into Institutional Culture
}

\section{ABSTRACT}

This paper offers a guide for those seeking to integrate the Scholarship of Teaching and Learning (SoTL) into higher education institutions to improve the quality of student learning. The authors posit that weaving SoTL into institutional cultures requires the coordinated actions of individuals working in linked social networks rather than individuals acting in isolation. Analyzing both the barriers and potential pathways to integrating SoTL into institutional cultures, the authors provide a conceptual model along with examples of practical strategies for overcoming resistance to change within institutions. The paper provides examples from a variety of different international contexts to show how incentives and other non-coercive measures can motivate faculty and administrators to weave SoTL into institutional fabrics.

Drawing on social network theory and the concept of communities of practice, the paper presents a model with attendant strategies for disseminating SoTL values and practices across all three levels of postsecondary institutions: the micro, the meso, and the macro. The authors argue that for SoTL to take root in organizational cultures, there must be 1) effective communication and dissemination of SoTL activity across all levels, 2) well established social networks and links between these levels (nodes), and 3) sustained support by senior administration. The authors conclude by suggesting ways their model could be tested.

\section{KEYWORDS}

model for integrating SoTL, SOTL and institutional culture, social networks in higher education, change in higher education

A departmental committee has been asked to develop a policies and procedures document in response to growing concerns that plagiarism is on the rise. There was a time when 
the committee would have started its deliberations by sharing anecdotes about "students these days," and by providing their personal views on the prevalence of cheating and why it is escalating. They might then have concluded that "something must be done" and that a "get tough policy" with corresponding procedures is in order.

There is a vision of academia's future, however, that yields a different set of deliberations. In this vision, the first thing the committee members do is ask for evidence that plagiarism is, in fact, on the rise, and if so, by how much and in what ways? If the evidence supports the general belief, then someone asks, "What does the literature tell us about plagiarism?" This question would trump the telling of personal anecdotes and the generation of unsubstantiated theories.

Given the prominence of the issue, at least one committee member would likely be familiar with this literature. She ${ }^{1}$ might point out that the topic is referred to as "academic integrity," and that there have been several large and rigorous studies conducted to determine both its prevalence and causes (see Freeman, Clarkeburn, \& Treleaven, 2007; Christensen Hughes \& McCabe, 2006; McCabe, 2004; McCabe \& Trevino, 1997). This would be followed by a discussion of the extant literature on the topic. She would report that plagiarism and other forms of cheating are generally on the rise and that changes in student attributes are only one possible cause. Rather than presenting a rant about "students these days," she provides the committee with findings to indicate that student perceptions of the learning environment are very predictive of their academic integrity, and that these perceptions can be affected by instructor behavior and messages about how the department values that integrity. She also informs the committee of the key role of institutional context, especially student culture, in understanding and addressing academic integrity (Freeman et al., 2007). The policies and procedures recommended by the committee would reflect these research findings. The committee might even identify studies that could fill current gaps in the literature and collaborate to undertake such a study.

This vision of academia's future - where inquiry, evidence, and innovation in teaching and learning are part of the fabric of everyday life-is just one example of what integrating SoTL into institutional cultures might look like. Rather than an improbable utopian parable, we believe that visions like this are attainable, and that faculty in the not-so-distant future may look back with surprise at the capricious ways teaching and learning are treated in some classrooms and institutions today. However, unless we're able to effectively integrate SoTL into institutional cultures, visions like this will remain mere pipe dreams.

For sustained and sustainable engagement with student learning, SoTL must be woven into the fabric of our institutions, rather than reliance on individuals operating in isolation. As Major and Palmer (2006) found, institutional support plays an important role in transforming faculty and improving teaching and learning (p. 642). However, like Martensson, Roxå, and Olsson (2011), we see SoTL as a means of not only developing individual staff and faculty members, but more importantly improving the ability of institutions to support student learning (p. 52). Integrating SoTL is essential for higher education because improving the quality of student learning requires an evidence-based approach, particularly at research-intensive institutions (Asmar, 2004). Moreover, institutional culture is not incidental to individual engagement with SoTL: Haigh, Gossman, and Jiao (2011) found that it is one of four key elements that influenced participants' likelihood to engage with SoTL, along with more time, more professional development opportunities, and more collegial interaction and support (p. 17). 
As in the early days of SoTL, we must carefully define our terms. By institutional culture, we refer to the entrenched behaviors of individuals working within organizations as well as the common "values, assumptions, beliefs or ideologies that members have about their organization or its work" (Peterson \& Spencer, 1991, as cited in Kezar \& Eckel, 2002, p. 142). In this paper we refer to transforming institutional cultures through SoTL as "weaving" and "integrating." "Weaving" is a fitting metaphor for bringing together the multiple and sometimes disparate threads that comprise institutional culture, for such work is a craft that involves using skills such as conceptualizing, designing, decision making, and coordinating. Similarly, the term "integrating" captures the bringing together of different activities and individuals engaged in SoTL work at all levels, which is essential for institutional change.

This paper is intended as a guide or a map of opportunities for SoTL travelersstudents, faculty members, faculty developers, and administrators - seeking to change their institution's culture to improve student learning. To bring conceptual clarity to this complex work, we've developed a model that shows how SoTL practices can be disseminated across the three major levels of organizations: the macro, the meso, and the micro, which we've developed from Poole and Simmons' (2013) exploration of the relation between SoTL and institutional quality. To demonstrate how the model has worked and could work in a variety of institutional settings, we've used examples from our collective experiences. Recognizing that institutional (as well as disciplinary and national) cultures shape both the obstacles and opportunities available to each of us, the map of opportunities drawn here provides multiple patterns for weaving SoTL into institutional culture. However, before laying out the various levels within organizations and strategies for changing them, we need to first address the opportunities and constraints individuals face.

\section{THE ROLE OF INDIVIDUALS IN INSTITUTIONAL CHANGE: LEARNING TO RECOGNIZE OPPORTUNITIES IN THE FACE OF BARRIERS}

To become change agents, individuals must first recognize the impediments to change, identify the channels through which change can occur, and understand the potential roles available to them. We begin, therefore, by considering barriers to organizational change and then suggest ways for individuals to seize opportunities in the face of these barriers to facilitate change.

Several studies have discussed how individual resistance works against integrating SoTL into institutional culture, as well as some of the underlying psychological causes of this resistance, such as confirmation bias (our tendency to favour information that confirms our beliefs), aversion to uncertainty (our preference for known over unknown risks), and the loss aversion/endowment effect (our tendency to prefer avoiding losses more than acquiring gains) (Mueller, Melwani, \& Goncalo, 2011; Simkins, 2012; Tagg, 2012). While understanding the psychological bases for resistance is vital, economic factors also play a role. The current global climate of fiscal austerity means fewer faculty have increased administrative and teaching responsibilities. Like anyone else, academics typically choose to invest their limited resources in meeting the demands of daily survival. Students need attention now, student work needs to be marked now, the department meeting is about to begin now, and it will be immediately followed by a supervision meeting, and then a lecture, which needs to be prepared ... yesterday. In the face of these urgent demands, the call to integrate SoTL into daily practice is unlikely to be heeded unless it is immediately 
useful and its benefits made clear. If the SoTL idea takes the form of a suggestion from a colleague, it may be ignored by the harried faculty member reluctant to take risks with teaching, and if it is issued as a directive by senior management, it may be dealt with in as perfunctory a manner as possible. Long-term strategies, especially those imposed from above, are often ignored (or openly dismissed) by individuals trying to just get through the day, the week, the term, or the national research assessment exercise. This should not be surprising, for indeed research suggests that our students take exactly the same approach when they are over-assessed (Ramsden, 1992, p. 171-73). Psychology also tells us that if faculty and staff do not believe that change will directly benefit them, they will resist it not only because the outcome is uncertain but also to avert any possible negative outcomes, including lost time that could have been spent doing something more rewarding (Tagg, 2012). These are examples of the "uncertainty aversion" and "loss aversion" effects. Simkins (2012), Mooney (2011), and Mueller et al. (2011) address additional factors in individual resistance to change. Notably, Craig (2004) found that resistance to organization change is unavoidable and not necessarily negative so those wanting to change culture must understand the nature and sources of resistance.

In the context of higher education institutions, individuals experience pressures from departments, professional disciplinary networks (Gibbs, Knapper, \& Piccinin, 2008), faculty, and university community (or "employer") to name a few. Disciplinary affiliations exert some of the strongest pulls on individuals in higher education, giving academics security by creating a strong sense of professional identity (Henkel, 2005). Departments often serve as our homes on campus; however, disciplinary ties can also be constraining and work against pedagogical development by encouraging insularity and conformity among faculty. But if departments are the places where barriers to change exist, they are also important loci for change. As Healey, Bradford, Roberts, and Knight (2013) showed in their study of curriculum change, discipline-based departmental teams can play a key role in not only curricular but institutional change, since departments are usually "the key organizational unit within which the core teaching and learning experiences of students are designed and implemented” (p. 31). Moreover, Roy, Borin, and Kustra's (2007) study of curricular change demonstrated that lasting change is more likely when it is departmentally based, and this may also turn out to be the case with SoTL. So what roles can the individual play in disciplinary or departmental change? Roy et al. identify three distinct roles that individual faculty members can play in facilitating change within departments, options that are helpful for conceptualizing how SoTL can be integrated into departmental and institutional cultures: (1) "initiators" are themselves champions of change or can identify people in positions of power who can act as champions and can bring about change by initiating discussions, inviting others to join, suggesting ideas, and introducing new resources; (2) "implementers" join and participate in existing change initiatives; and (3) "cultivators" lay the groundwork for future change by creating a climate conducive to change (p. 30-31). Such an inclusive notion of change agents is helpful for the project of integrating SoTL into higher education cultures because it legitimizes the multiple roles individuals can play in precipitating change, whether at the department or institutional level.

In addition to disciplinary and departmental barriers to and opportunities for change, individual members seeking to effect cultural change also experience pressures from social 
or professional norms, government and employer policies, financial constraints, and processes related to tenure, promotion, or other forms of local/national evaluation, depending on one's particular organizational context. Individuals wanting to stimulate change-local SoTL champions-must therefore adopt flexible approaches that suit their specific contexts to overcome these pressures. For as Martensson, Roxå, and Olsson (2011) showed, strategies are most effective when they are aligned with organizational culture. Instead of confronting faculty resistance to change head-on, it may be more productive to identify areas where there is less resistance, or greater opportunity, to put it more positively. For example, a junior lecturer may quickly exhaust her social capital (and optimism) trying to convince senior colleagues to adopt more effective assessment methods. But that same effort could be more profitably channeled into documenting and disseminating evidence of the efficacy of her own methods, and teaching them to younger colleagues, particularly contract lecturers and graduate students who are eager both to become more competent teachers and to accrue evidence of that competence in their dossiers. In this way, individuals who lack formal institutional power can still act as informal leaders within teaching and learning (Billot et al., 2013). Similarly, if individuals working in senior administration recognize that faculty may resent and mistrust strategies based on compliance mechanisms, strategies based on tangible incentives and rewards could prove to be highly effective. For example, if faculty members resist investing in SoTL because they see it as interfering with their tenure and promotion goals (as is sometimes the perception at research-intensive institutions), then an effective strategy might be to include engagement with SoTL in promotion criteria.

Providing tangible incentives and support for SoTL is key to ensuring it becomes woven into institutional cultures. Some institutions offer certification courses in higher education and reward academic staff with promotions or salary increments for earning these advanced teaching qualifications. For example, institutions like Victoria University of Wellington fund research to develop and disseminate better teaching practices. Such funding provides both material (e.g., money) and immaterial (e.g., prestige) rewards to faculty for actively seeking to improve their teaching. At the other end of the university hierarchy are junior faculty and graduate students who rarely have direct influence over policymaking. Nonetheless, this group can exert influence by participating in and disseminating SoTL research, and thereby earn greater credibility in their local spheres of influence.

Because of the complexity of institutional structures, networking with others who may see our problem differently is helpful for identifying opportunities. After all, one of the most challenging barriers facing SoTL champions is isolation. Developing a critical mass of SoTL champions to allow social networking and cross-fertilization of ideas is crucial to avoiding isolation and disillusionment. For example, Edinburgh Napier University's Teaching Fellows program, which recognizes and rewards individuals engaged in SoTL, is an example of how SoTL champions can be encouraged by the institution (Edinburgh Napier, 2012). An institution that helps acculturate newer faculty to SoTL and values and nurtures social networks of SoTL champions can also help ensure that institutional change is lasting. As Martensson et al. (2011) found, commitment to teaching and learning can be enhanced by cultivating "significant networks" through faculty SoTL initiatives (p.59). By involving academic staff, especially new faculty, in the devel- 
opment and implementation of learning and teaching assessment strategies and other SoTL-related initiatives, individual SoTL champions can create social networks, which ensure that SoTL practices become fully integrated into the institution over time. The next section discusses in greater detail how individuals can come together to work in social networks.

\section{TRANSFORMING INSTITUTIONAL CULTURE THROUGH SOCIAL NETWORKS}

Organizational culture is complex and a bit intimidating, especially when one is attempting to effect change, yet the success of institutional transformation largely depends on the ability of change agents to understand culture (Craig, 2004). Cultural change occurs slowly and culture "perpetuates and reproduces itself" (Schein, 1990, p.115) through social networks rather than through the actions of a few isolated individuals. Culture needs to be modeled for incoming faculty, middle management, and others to encourage uptake and to perpetuate cultural values (Ginsberg \& Bernstein, 2011). Eventually, if enough people accept new cultural values, there is a kind of "tipping point" (Gladwell, 2002) whereby a "new" element of the culture, such as SoTL, becomes a norm.

Understanding the structure of the organization one is trying to influence is essential for developing strategies to increase the value of SoTL work in a culture. Higher education institutions are distinct from other organizations in their emphasis on the individual, discipline-based career (Craig, 2004, p. 84). Figure 1 below adapts Poole and Simmons' (2013) three-level structure of teaching within higher education: the microsocial (individual instructors), the mesosocial (instructors working collaboratively), and macrosocial (senior administrators governing the entire institution). Our model shows the three main levels of a typical postsecondary institution's structure - micro, meso, and macro-as well as the interactions among these levels. At the base of the pyramid is the micro-level where the activities of individual faculty members, staff, and students reside. The mesolevel represents middle management, including deans and department chairs, who act as conduits of information both upwards to senior management and downwards to individual faculty members and students. The macro-level at the top of the pyramid is where the strategic direction for the institution as a whole is established. The arrows within the model represent the permeability of the levels (micro, meso, and macro), and the dotted and solid lines indicate the connections (both strong and weak ties) that can develop between individuals and communities of practice (CoPs), which are "groups of people who share a passion for something that they know how to do and who interact regularly to learn how to do it better" (Wenger, McDermott \& Snyder, 2002, p. 1).

If culture is more effectively disseminated through social networks rather than through the actions of a few isolated individuals, then integrating SoTL into institutions requires building and sustaining social networks. Communities of practice give members access to expertise, support for problem solving and knowledge sharing, and promote synergies across departments, units, or other groups (Wenger et al., 2002) and function as social networks. CoPs that are formed around teaching and learning are examples of small, tightly bonded networks. Granovetter's (1973) analysis of the interactions between the micro- and macro-levels within an organization elucidated how social networks within organizations work. Notably, Figure 1 above shows not only CoPs, but also the few individuals in each social network or cluster who provide links between different networks, 


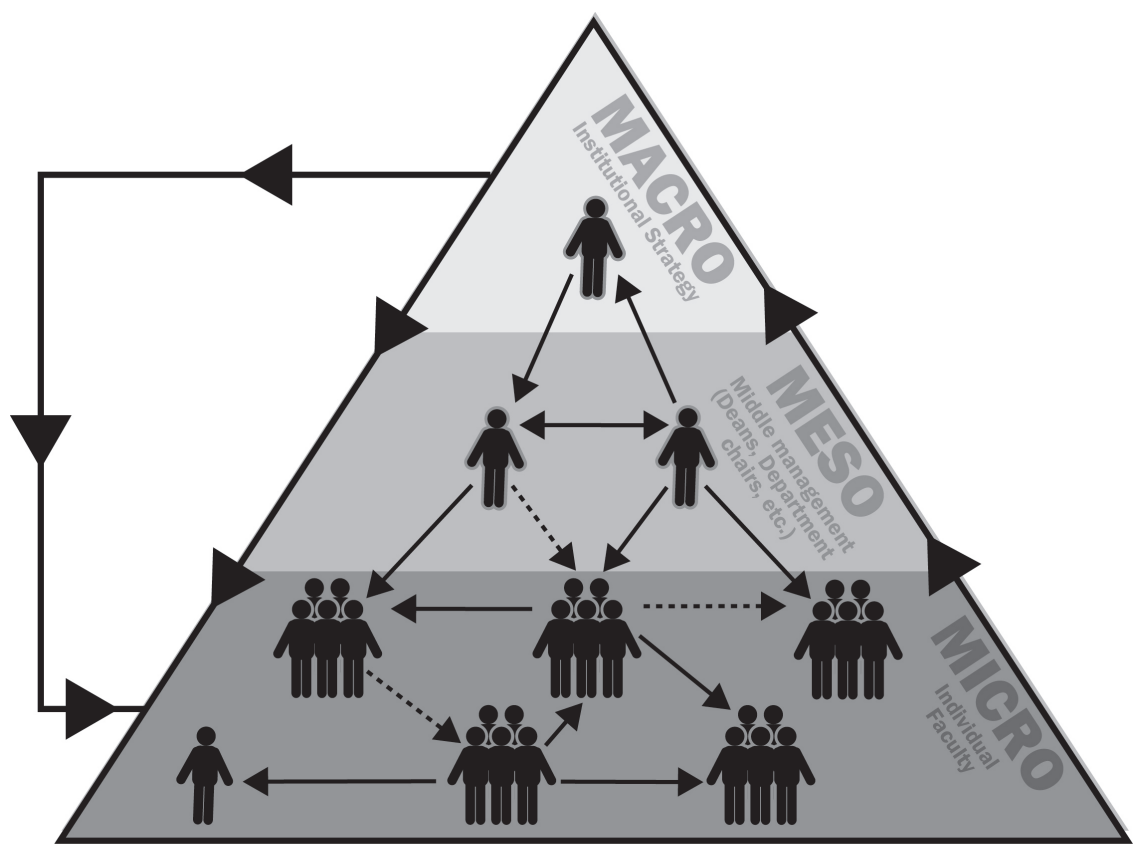

Macro Level: Sets the strategic direction

Meso Level: Interprets key issues and acts as conduit of information both upwards and down

Micro Level: Activities of communities of practice, individual faculty and students

Figure 1. Social Network Formation across Micro-, Meso-, and Macro-Levels in a Higher Education Institution.

which Roxå and Martensson (2009), building on Granovetter (1973), call “hubs.” We prefer to call these nodes, since the term better suits the organic nature of our model.

The concept of nodes is a key element of our model, for nodes facilitate communication and diffusion of the values, beliefs, and practices across different social networks and levels and thereby enable coordinated action. The meso-level in the model is essential to bridging the gap between the micro- and macro-levels, for although change agents can be found at all levels, individuals and CoPs working at the micro-level often lack the power and access to macro-level leaders (and the attendant resources) required to implement change within larger cultural structures. Those working at the meso-level (such as deans and department chairs) therefore have the potential to play a key role in bridging the gap between the micro and macro. In the next section, we show how the model could be applied to integrate SoTL into institutional culture.

\section{APPLYING THE MODEL}

Our model assumes that the isolated actions of a scattered few do not make a culture. Working from this assumption, the model helps us understand how SoTL can move from isolated action to cultural norm. To apply the model, we propose the use of three necessary and inter-related processes: (1) communication and dissemination, (2) social network development, and (3) sustained support. We argue that these three elements must be vibrant and closely linked for an academic culture to grow and flourish. In this 
section of our paper, we explain each of these processes and use the model to explore how SoTL can be woven into institutional culture.

\section{Communication and Dissemination}

The need for effective communication figures prominently in a number of places within the model, including between members of the social networks within as well as across the three levels. Communication is key for integrating SoTL into institutional culture. Major and Palmer (2006) found that faculty members' ability to gain "a vocabulary to discuss teaching with their colleagues and with a national audience" was an important marker of institutional change (p. 643). Communication is not only important at the micro-level where individual faculty operate, but also at the macro- and meso-levels. In their examination of how leaders influence higher education culture, Roxå and Martensson (2013) identified the need for leaders to move "backstage conversations" about teaching and learning "into the open" for institutional change to occur (p. 4). Communication is also required to ensure that one is not engaging in isolated actions. Dissemination is a particular form of communication that is intended to spread the word about the nature and extent of SoTL work within institutions. Poole and Simmons (2013) found that dissemination is required to spread good teaching practices and improve institutional quality, but we believe that dissemination can potentially do even more than impact quality. Events like SoTL mini-conferences and in-house publications can also help build networks that are instrumental in the spread of cultural norms. Communication and dissemination can also facilitate social network development.

All three levels of the model are essential for the weaving of SoTL into an institution's cultural fabric. Of the three, the meso-level is crucial to ensuring dissemination and communication up and down our model. As SoTL evolves to become an integral part of an institution's culture, reciprocity builds between micro-level SoTL activity and macro-level support. With the meso-level acting as a purposeful and active conduit, SoTL activity can stimulate macro support, which in turn can help SoTL activity become woven into the culture. Institutions must develop leadership at both the macro- and meso-levels that is able to support SoTL engagement at the micro-level (Martensson et al., 2011). Those working at the macro-level can begin by adopting not only the values but also the language of SoTL to describe teaching and learning at their institutions, citing evidence of learning and collaborations in SoTL research. Recognition for SoTL work then increases. Eventually, like in our opening vignette, the members of the institution can no longer imagine a time when SoTL was merely the isolated actions of a scattered few.

\section{Social Network Development}

Social networks are a way for members to establish and share cultural norms (Kennedy, 1998). Through networks, SoTL practitioners come to realize that they are not alone, that shared values and behaviors exist (Roxå \& Martensson, 2009). These realizations are among the building blocks of culture. Some of these social networks come into existence via happy coincidence. People talk to others about their research on student learning, and they realize they have SoTL work in common. However, institutions cannot rely on such coincidences to build culture. As our model indicates, we need people working at the meso-level to serve as hubs or nodes for these social networks. Often these are the people working in educational development centers or other units dedicated to the sup- 
port of SoTL on a campus. Alternatively, these may be department chairs or heads who work closely with others outside of their unit and return to their disciplinary or departmental homes with new ideas and resources. People serving nodal functions are in the unique position to see possible connections among individuals working at the micro-level, and they have the skills and connections to bring people belonging to different groups together, both within and across disciplines. People serving this nodal function create "weak ties," which do not involve emotional closeness, yet which can facilitate access to information and resources and coordination (Granovetter, 1973). When we talk about weaving SoTL into institutional culture, these people working at the meso-level-the deans, department chairs, and educational developers - are weavers.

The skills required for these nodal positions cannot be taken for granted; rather, they must be cultivated through communities of practice for these key individuals. Leadership development programs could provide opportunities for such communities to be built and joined. These CoPs can be supported by organizations such as ISSOTL. Still, even if skilled individuals are in place at the meso-level, social networks and the culture they are shaping will falter without sustained support.

\section{Sustained Support}

Sustained support for institution-wide culture change typically requires the involvement of organizational members, such as senior administrators, working at a macro-level. In our model, though, culture is not necessarily created by the actions of these people. Rather, it is supported and sustained by them. The distinction is an important one: the former speaks to a coercive approach, the latter to a non-coercive one. Our model assumes that a non-coercive approach is required for sustained support of culture within academia since coercion is rarely an effective change strategy in higher education. The adage "culture eats strategy for breakfast" reminds us that one cannot create change simply with macro-level strategies. Rather, micro-level cultural beliefs and practices will trump such strategies and may prompt people working at micro-levels to devise means of creative non-compliance with macro-level strategies and policies. As Roxå and Martensson argued, "a leader can never control a culture; it is much more likely that the culture controls the leader" (2013, p. 8).

In fact, the most lasting supports for actions within academic culture do not take the form of occasional administrative policies and edicts, but of widely shared values and beliefs within departments and eventually across the entire institution. While rules and rewards might flow from these values and beliefs, it is the values and beliefs themselves and not the rules that are the more powerful source of sustained support. At the same time, those at the macro-level can certainly help create a more supportive environment in which a culture of SoTL can flourish. For example, investing in the development of social networks for disseminating SoTL practice and in rewards for SoTL excellence (Strickland, McLatchie \& Pelik, 2011) is one strategy to integrate SoTL into institutional culture in a meaningful and lasting way.

An example of a long-standing and supported practice in academic culture is peer review. Institutions have rules about peer review for publication, funding, and promotional decisions, and these rules are expected by members of the culture. However, the rules are not what sustain the practice of peer review; rather, it is sustained by the shared belief in its importance (for a historical analysis of peer review see Biagioli, 2002). 
In our opening vignette, we portrayed the process of curricular decision-making as being shaped by the shared belief that such decisions should be based on scholarship. When that belief is as widely held as the belief in the importance of peer review, macrolevel policies and support for SoTL will emerge. Engagement with scholarship about teaching and learning must become a part of the culture in the same way peer review is the part of the fabric of higher education culture (Martensson et al., 2011, p. 54). But isn't the belief and practice that decisions should be based on scholarship already an integral part of academic culture? Oddly, this seems not to be the case when it comes to teaching and learning. We can use our three-level model to help us envision how this can change so decisions are based on scholarship and a greater proportion of the institution's membership is engaged in creating that scholarship.

The cultivation of SoTL networks within an institution is a precarious process, partly because the macro-level may not yet be fully engaged, and partly because the communication required to make something culturally normative is daunting, especially at large institutions. Nevertheless, the important work of building and preserving social networks continues with the establishment of SoTL institutes and research groups, and institutions do change over time. ${ }^{3}$

Our model presents an optimistic view. While recognizing significant challenges, it predicts that SoTL can be woven into institutional culture. Being non-coercive, the model assumes that SoTL work is something that a critical mass of academic staff is intrinsically motivated to pursue. When they find out that others are engaging in SoTL, they will be magnetically drawn to the work. This is, of course, a naïve assumption. The work of communication and dissemination, social network development, and sustained support must be done to create a "tipping point" (Gladwell, 2002), so SoTL activity takes root, providing those at the meso-level with convincing evidence to take up to the macrolevel.

\section{FUTURE DIRECTIONS: TESTING THE MODEL}

In this paper, we have provided a map of opportunities for those seeking to improve student learning by changing institutional culture to value and reward SoTL work. We have presented a model depicting the barriers as well as potential routes, such as communities of practice and social networks, to weaving SoTL into the micro-, meso-, and macro-levels of institutions. However, there is much work to be done to raise the profile of SoTL and to promote the cultural shifts necessary to ensure that SoTL is woven into the fabric of higher education institutions. Models, of course, must be tested, and maps must be redrawn after further exploration. We need to amass evidence that evaluates both the empirical and theoretical relationships among our concepts. Institutions where SoTL thrives could be studied and relationships among the various levels and social networks that work across them examined to learn how people, ideas, and practices travel within institutions.

The role of change agents is difficult in any organization, but particularly in the context of academic cultures where individuals negotiate multiple and sometimes conflicting roles and responsibilities: the individual academic is a subject expert, a pedagogy expert, and a teaching and learning research expert, but we need to learn how our colleagues see these roles interacting. For example, what are the effects of disciplinary and departmental norms, possibly developed at micro-levels, and intramural funding initiatives provided by 
macro-levels on individual engagement with SoTL, and, most importantly, how do these cultural norms inform teaching and learning practices? How can macro-level policies for promotion and tenure foster SoTL productivity among faculty, and, conversely, how can individuals working at the micro-level effect change at the meso- and macro-levels? Above all, we need to learn more about the outcomes for students of integrating SoTL into institutional cultures (Asmar, p. 65). For instance, what is the relation between how SoTL is integrated into institutional cultures and student success and retention in different institutional contexts? In other words, how is student learning impacted by having SoTL integrated into institutional cultures? Although a broad array of indicators such as how we understand and talk about teaching, how we define and evaluate scholarship, and the level of engagement with SoTL by faculty are useful indicators of institutional change, as Haigh et al. (2011) remind us, the impact on student learning must remain our primary concern (p. 19).

Kezar, Gallant, and Lester's (2011) study examined how faculty and staff can stimulate change from the bottom up in organizations through various tactics such as building social networks, and they found successful organizational change requires that strategies be carefully aligned with organizational culture. This suggests some areas for future research that test our model, such as exploring which tactics are most effective in different contexts for improving communication, building social networks, and developing sustained support for SoTL. Case studies that build on Martensson et al.s exploration of a strategy to improve teaching and learning at Lund University (2011) would help us understand how cultural change initiatives can improve the quality of teaching and learning in different settings.

Our paper provides a road map for changing organizations through various strategies, beginning at the micro-level. These strategies could be tested for their effectiveness in developing grassroots SoTL leadership and followership (Billot et al., 2013) as well as fostering change at the meso- and macro-levels of institutions. In addition to examining grassroots SoTL leadership development, Kezar et al. (2011) discussed the concept of "tempered radicals"-activists who are firmly committed to their organizations, but who are also committed to a cause that may not be embraced by the existing hierarchy. The framework of the tempered radical is both a useful and inspiring one for those of us seeking to weave SoTL into our department's and institution's culture in the service of improved teaching and learning, because like Billot et al.'s (2013) work on followership, it reminds us that we can all be agents of change, whether or not we occupy positions of formal leadership. The model presented here reminds us that we are most powerful and effective when we work not alone, but as part of coordinated social networks, which can become "change networks" (Kezar et al., 2011, p. 149) working within institutions to transform student learning.

Andrea L. Williams is a Lecturer in the Faculty of Arts and Science at the University of Toronto where she directs a Writing Across the Curriculum program.

Roselynn Verwoord is a PhD Student in Educational Studies and the Evaluation and Research Coordinator at the Centre for Teaching Learning and Technology, University of British Columbia.

Theresa A. Beery, PhD, RN, ACNP-BC, CNE is a Professor and Director of the Center for Educational Research, Scholarship, and Innovation at the University of Cincinnati College of Nursing. 
Helen Dalton is a Senior Lecturer in the School of Business at the University of Sydney and a Higher Education Learning and Teaching Consultant.

James McKinnon is a Lecturer in the Theatre Programme at Victoria University of Wellington.

Karen Strickland is a Senior Lecturer and Senior Teaching Fellow in the Academic Practice team in the Office of the Vice Principal (Academic) at Edinburgh Napier University.

Jessica Pace is a PhD Student in the Department of Anthropology at McMaster University in Hamilton, Ontario, Canada.

Gary Poole is the Associate Director of the School of Population and Public Health and Senior Scholar in the Centre for Health Education Scholarship at the University of British Columbia.

\section{NOTES}

1. We use the feminine pronoun to refer to academics throughout our paper to avoid having to use the more awkward "he/she."

2. This popular catchphrase is widely attributed to the influential management theorist Peter Drucker; however nowhere is it specifically cited as originating in one of Drucker's many publications.

3. For example, the UK Professional Standards Framework (PSF), which outlines a national framework for recognizing and assessing teaching and learning in Higher Education, is one of the ways institutions in the UK are seeking to assign greater value to teaching and learning practice across all institutions, including those that are research intensive. The PSF is in part a response to the 1997 Dearing Report, which called for all academics to become Fellows of the Higher Education Academy. The PSF now forms part of institutional reporting and annual quality monitoring.

\section{REFERENCES}

Asmar. C (2004). Innovations in scholarship at a student-centered research university: An Australian example. Innovative Higher Education, 29, 49-65. Retrieved from http://www .springer.com/education+\%26+language/higher+education/journal/10755

Biagioli, M. (2002). From book censorship to academic peer review. Emergences: Journal for the Study of Media \& Composite Cultures, 12(1), 11-45. doi: 10.1080/1045722022000003435

Billot, J., West, D., Khong, L., Skorobohacz, C., Roxå, T., Murray, S., \& Gayle, B. (2013). Followership in higher education: Academic teachers and their formal leaders. Teaching and Learning Inquiry: The ISSOTL Journal, 2(1).

Christensen Hughes, J. M., \& McCabe, D. L. (2006). Academic misconduct within higher education in Canada. Canadian Journal of Higher Education, 36(2), 1-21. Retrieved from http://ojs .library.ubc.ca/index.php/cjhe/article/view/183537

Craig, C. (2004). Higher education culture and organizational change in the $21^{\text {st }}$ century. The Community College Enterprise: A Journal of Research \& Practice, 10(1), 79-87. Retrieved from http://www.schoolcraft.edu/cce/

Dearing, R. (1997). Higher education in the learning society. The report of the National Committee of Inquiry into Higher Education (The Dearing Report). Retrieved from https://bei .leeds.ac.uk/Partners/NCIHE/ 
Edinburgh Napier University. (2012). Teaching Fellowship Scheme. Retrieved from http://staff .napier.ac.uk/services/academicdevelopment/TFscheme/Pages/welcome.aspx

Freeman, M., Clarkeburn, H., and Treleaven, L. (2007). A collaborative approach to improving academic honesty. In A. Brew and J. Sachs (Eds.) Transforming a university: The scholarship of teaching and learning in practice (pp.153-161). Sydney: Sydney University Press.

Gibbs, G., Knapper, C., \& Piccinin, S. (2008). Disciplinary and contextually appropriate approaches to leadership of teaching in research-intensive academic departments in higher education. Higher Education Quarterly, 62, 416-436. doi: 10.1111/j.1468-2273.2008.00402.x

Ginsberg, S.M., \& Bernstein, J.L. (2011). Growing the scholarship of teaching and learning through institutional culture change. Journal of the Scholarship of Teaching and Learning, 11(1), 1-12. Retrieved from http://josotl.indiana.edu/article/view/1806/1803

Gladwell, M. (2002). The tipping point: How little things can make a big difference. Boston: Little Brown.

Granovetter, M.S. (1973). The strength of weak ties. American Journal of Sociology, 78, 13601380. doi:10.1086/225469 http://www.jstor.org/stable/2776392

Haigh, N. Gossman, P. \& Jiao, X. (2011). Undertaking an institutional 'stock-take' of SoTL: New Zealand University case studies. Higher Education Research \& Development: Journal of the Higher Education Research and Development Society of Australasia, 30, 9-23. doi:10 $.1080 / 07294360.2011 .536969$

Healey, M., Bradford, M., Roberts, C. \& Yolande, K. (2013). Collaborative discipline-based curriculum change: Applying Change Academy processes at department level, International Journal for Academic Development, 18(1), 31-44.

Henkel, M. (2005). Academic identity and autonomy in a changing policy environment, Higher Education: The International Journal of Higher Education Research, 49(1/2), 155-176. Retrieved from http://www.springer.com/education+\%26+language/higher+education /journal/10734

Kennedy, J. (1998). Thinking is social: Experiments with the adaptive culture model. The Journal of Conflict Resolution: Journal of the Peace Science Society (International), 42(1), 56-76. doi:10.1177/0022002798042001003

Kezar, A., \& Eckel, P.D. (2002). The effect of institutional culture on change strategies in higher education: Universal principles or culturally responsive concepts? The Journal of Higher Education, 73, 435-460. doi:10.1353/jhe.2002.0038

Kezar, A., Gallant, T.B., \& Lester, J. (2011). Everyday people making a difference on college campuses: The tempered grassroots leadership tactics of faculty and staff. Studies in Higher Education, 36(2), 129-151. doi:10.1080/03075070903532304

Major, C.H. \& Palmer, B. (2006). Reshaping teaching and learning: The transformation of faculty pedagogical content knowledge. Higher Education: The International Journal of Higher Education Research, 51, 619-647. doi: 10.1007/s10734-004-1391-2

Martensson, K., Roxå, T., \& Olsson, T. (2011). Developing a quality culture through the scholarship of teaching and learning. Higher Education Research \& Development: Journal of the Higher Education Research and Development Society of Australasia, 30(1), 51-62. doi: 10.1080/07294360.2011.536972 
McCabe, D. (2004). Ten (updated) principles of academic integrity: How faculty can foster student honesty. Change: The Magazine of Higher Learning, 36(3). 10-15. doi:10.1080 /00091380409605574

McCabe, D., \& Trevino, L. (1997). Individual and contextual influences on academic dishonesty: A multi-campus investigation. Research in Higher Education: Journal of the Association for Institutional Research, 38, 379-396. Retrieved from http://link.springer.com /article/10.1023/A\%3A1024954224675

Mooney, C. (2011, May/June) The science of why we don't believe science. Retrieved from http://www.motherjones.com/politics/2011/03/denial-science-chris-mooney

Mueller, J. S., Melwani, S., \& Goncalo, J. A. (2011). The bias against creativity: Why people desire but reject creative ideas. Psychological Science: Research, Theory, \& Application in Psychology and Related Sciences, 23(1) 13-17. doi:10.1177/0956797611421018

Peterson, M. \& Spencer, M. (1991). Understanding academic culture and climate. In M. Peterson (Ed.), ASHE reader on organization and governance (pp. 140-155). Needham Heights, MA: Simon and Schuster.

Poole, G., \& Simmons, N. (in press). Contributions of the scholarship of teaching and learning to quality enhancement in Canada. In R. Land \& G. Gordon (Eds.) Enhancing quality in higher education: International perspectives. London: Routledge.

Ramsden, P. (1992.) Learning to teach in higher education. London: Routledge.

Roxå, T. \& Martensson, K. (2009). Significant conversations and significant networks—exploring the backstage of the teaching arena. Studies in Higher Education, 34, 547-559. doi:10.1080 103075070802597200

Roxå, T., \& Martensson, K. (in press). How leaders can influence higher education cultures. Perspectives on Pedagogy and Practice. Retrieved from http://www.ulster.ac.uk/centrehep /journal.html

Roy, D. Borin, P. \& Kustra, E. (2007). Assisting curriculum change through departmental initiatives. New Directions for Teaching and Learning, 112, 21-32. doi: 10.1002/tl.295

Schein, E.H. (1990). Organizational culture. American Psychologist: Journal of the American Psychological Association, 45(2), 109-119. doi:10.1037/0003-066X.45.2.109

Simkins, S. (2012, October). Addressing faculty resistance to change: Broadening and extending SoTL's impact on teaching and learning. Paper presented at the Conference for the International Society for Scholarship of Teaching and Learning. Hamilton, ON, Canada.

Strickland K., McLatchie J., \& Pelik, R. (2011) Reflections on the development of a dynamic learning, teaching and assessment strategy. Campus Wide Information Systems: The International Journal of Information and Learning Technology, 28, 294-298. doi: http://dx.doi .org/10.1108/10650741111162761

Tagg, J. (2012). Why does the faculty resist change? Change: The Magazine of Higher Learning. Retrieved from http://www.changemag.org/Archives/Back\%20lssues/2012/JanuaryFebruary $\% 202012 /$ facultychange-full.html.

Wenger, E., McDermott, R. \& Snyder, W. M. (2002). Cultivating communities of practice, Boston, MA: Harvard Business School Press. 